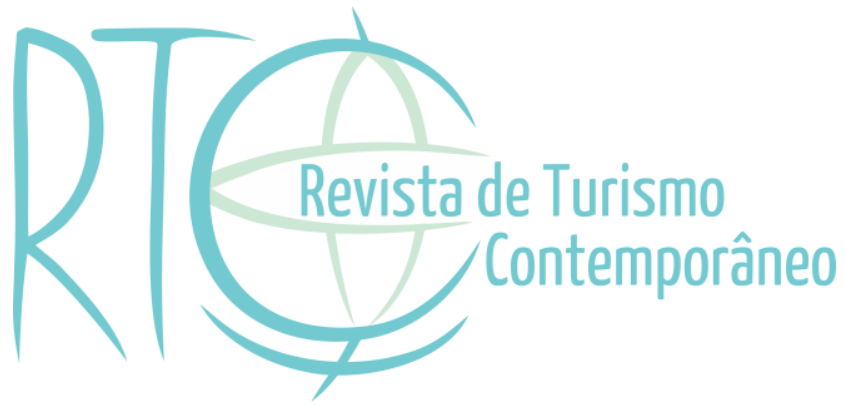

\title{
Estudo sobre ações sustentáveis para a organização de eventos em espaços livres de uso público
}

\section{Study on sustainable actions for organizing events in open public spaces}

\section{Mariana Cristina da Cunha Souza}

Docente do curso de Eventos na Faculdade de Tecnologia - Fatec, Presidente Prudente/SP, Brasil

E-mail: mariana.souza33@fatec.sp.gov.br

Dennis de Pádua

Tecnólogo em Eventos pela Faculdade de Tecnologia - Fatec, Presidente Prudente/SP, Brasil E-mail:paduadennis@hotmail.com 


\section{RESUMO}

Este artigo resulta de uma pesquisa de iniciação científica. O objetivo geral foi identificar os eventos realizados em espaços livres de uso público na cidade de Presidente Prudente/SP, demonstrando como podem ser estratégicos para o setor de Turismo e Eventos, possibilitando a incorporação de práticas e ações sustentáveis. A metodologia consistiu na revisão da literatura científica e pesquisa de campo auxiliada pela técnica da observação sistemática e entrevistas. Os resultados demonstram que, quanto aos impactos positivos com a utilização desses espaços para o eventos têm-se a valorização e possivelmente maiores investimentos financeiros nessas áreas; a efetiva apropriação dos espaços públicos, que reforçam e valorizam os elementos culturais e ambientais locais, melhorando a imagem da cidade e da gestão pública municipal; a utilização de elementos naturais da paisagem; maior mobilidade e participação de pessoas de diferentes grupos sociais, pois o acesso não é restrito. Os impactos negativos podem ser a degradação ambiental, com o descarte dos resíduos sólidos no chão, poluindo o ambiente e a paisagem; impactos sobre a vegetação existente na área, entre outros. A partir disso, considera-se que os espaços livres de uso público têm potencial para serem aproveitados, especialmente, como locais estratégicos na promoção de eventos com base nos princípios da sustentabilidade. Sugere-se aos organizadores de eventos, que no processo de planejamento, sejam pensadas práticas de sensibilização dos envolvidos, desde os organizadores até o público participante, ressaltando a importância da responsabilidade ambiental, a aplicação das ações sustentáveis e a utilização desses espaços para a realização de eventos na cidade.

Palavras-chave: Turismo. Eventos. Sustentabilidade. Espaço Público. Presidente Prudente.

\section{ABSTRACT}

This article is the result of a scientific initiation research. The objective was to identify the events held in open spaces for public use in the city of Presidente Prudente/SP, demonstrating how they can be strategic for the tourism and events sector by incorporating sustainable practices and actions. The methodology consisted of a review of the scientific literature and field research aided by the technique of systematic observation and interviews. The results show that, regarding the positive impacts with the use of these spaces for events, there is an appreciation and possibly greater financial investments in these areas; the effective appropriation of public spaces, which reinforce and value local cultural and environmental elements, improving the image of the city and municipal public management; the use of natural landscape elements; greater mobility and participation of people from different social groups, as access is not restricted. Negative impacts can be environmental degradation, with the disposal of solid waste on the ground, polluting the environment and landscape; impacts on existing vegetation in the area, among others. From this, it is considered that the open spaces for public use have the potential to be used, especially as strategic places in the promotion of events based on the principles of sustainability. It is suggested to event organizers that in the planning process, awareness-raising practices for those involved, from the organizers to the participating public, be considered, emphasizing the importance of environmental responsibility, the application of sustainable actions and the use of these spaces for the realization of events in the city.

Keywords: Tourism. Events. Sustainability. Public place. Presidente Prudente. 


\section{INTRODUÇÃO}

Este trabalho é resultado de um projeto de iniciação científica financiado pelo Conselho Nacional de Desenvolvimento Científico e Tecnológico (CNPq). O tema foi pensado, tendo como problemática: Como promover eventos mais sustentáveis na cidade de Presidente Prudente/SP, utilizando os espaços livres de uso público? Entende-se por eventos sustentáveis, aqueles cujo principal fundamento é minimizar impactos socioambientais negativos em todas as suas fases de planejamento: concepção, pré-evento, transevento e pósevento (Silberberg \& Macdowell, 2010; Smith-Christensen, 2009). A partir do entendimento de que os eventos influenciam nos deslocamentos turísticos e geram benefícios para as cidades em que são realizados, como a criação de emprego e renda, é importante um planejamento que esteja em harmonia com ambiente e a sociedade.

O Turismo de Eventos pode ser definido como "[...] o conjunto de atividades turísticas decorrentes dos encontros de interesse profissional, associativo, institucional, de caráter comercial, promocional, técnico, científico e social” (Brasil, 2006, p. 46). De acordo com Albuquerque (2004), esse tipo de turismo possibilita, antes de tudo, o enriquecimento cultural porque as pessoas viajam, muitas vezes, para um destino desconhecido por elas. Assim, potencializam através do planejamento estratégico de suas atividades, o interesse de visitação e exploração de determinada localidade.

Tomazzoni (2003) argumenta que os eventos geram riquezas tangíveis e intangíveis para a cadeia produtiva turística, conjugando fatores culturais, tecnológicos, políticos e econômicos. Por outro lado, podem ocasionar impactos negativos quando o projeto que será executado não considera as reais necessidades da cidade e comunidade.

A sustentabilidade associada aos eventos, portanto, é vista como estratégia para projetar a imagem da cidade perante a sociedade, o turista e os profissionais que atuam nesse mercado, minimizando os efeitos negativos da atividade ao pautar-se na qualidade ambiental, competitividade econômica responsável e valorização dos aspectos socioculturais locais e regionais (Silberberg \& Macdowell, 2010; Smith-Christensen, 2009).

Nesse sentido, o objetivo geral do artigo foi identificar os eventos realizados em espaços livres de uso público na cidade de Presidente Prudente/SP, demonstrando como podem ser estratégicos para o setor de Turismo e Eventos, possibilitando a incorporação de práticas e ações sustentáveis. Presidente Prudente é sede da $10^{\text {a }}$ Região Administrativa do estado de São Paulo e exerce função relevante na região conhecida como Alto Sorocabana, sendo o principal polo industrial, cultural e de serviços. Em relação ao Turismo de Eventos, a 
cidade apresenta uma importante tradição cultural, desde o artesanato até o teatro, a música, o esporte - onde oferece ampla infraestrutura em espaços livres de uso público destinados ao lazer (Lamberti \& Silva, 2018).

As informações disponibilizadas no Guia Cultural do Estado de São Paulo, de 2013, destacam que a Região Administrativa de Presidente Prudente possui uma diversidade de equipamentos culturais - anfiteatros, arquivos, auditórios, bibliotecas, casas da cultura, centros culturais, cinemas, conchas acústicas, museus, teatros e outros espaços culturais que podem incrementar o turismo regional, influenciando diretamente na demanda por eventos. Portanto, existe um potencial a ser explorado e desenvolvido por meio de políticas públicas em associação com as iniciativas privadas, promovendo a cidade e região como referência nos eventos associados à sustentabilidade socioambiental.

Por isso, o trabalho justifica-se como forma de propor um melhor aproveitamento dos espaços públicos da cidade, buscando a sensibilização e valorização dessas áreas pelo poder público e, especialmente, pela comunidade, de modo que ela se reconheça nelas, "criando relações de vivência e sentimento de pertença, estabelecendo territorialidades", por meio da participação em eventos. Do mesmo modo, espera-se contribuir para qualificar a oferta turística em Presidente Prudente, com foco no calendário oficial de eventos, uma vez que a Prefeitura Municipal tem buscado o título de Município de Interesse Turístico (MIT).

Para Lamberti e Silva (2018), quando o município anseia por esse título, é preciso obter ou desenvolver um potencial turístico, ou seja, é necessário ter a capacidade e competência para fomentar a atividade em escala local e regional, e isso acontece muito quando os eventos fazem parte do calendário proposto.

\section{2. eVENTOS SUSTENTÁVEIS E AS ÁREAS VERDES PÚBLICAS: RELAÇÕES E}

\section{PROCESSOS}

Na cidade, a captação de eventos é condicionada pelas parcerias entre os agentes públicos (secretarias de turismo, cultura, esportes, etc.) e os agentes da iniciativa privada (Convention Visitors Bureau, Conselho Municipal de Turismo e Associação Comercial). A atuação conjugada desses agentes é um desafio para o mercado de turismo e eventos, porém, quando efetivada, ajuda a racionalizar as atividades a serem desenvolvidas, gerenciar os recursos - financeiros e humanos disponíveis, e implantar projetos diversificados, de tal maneira que gere benefícios a todos os envolvidos (Meirelles, 1999; Gastal, 2007). 
Estudos disponibilizados pelo Ministério do Turismo (Brasil, 2006) apontam que o setor de festas relacionados ao Turismo de Eventos apresenta crescimento significativo, quando comparado aos outros setores da economia. As empresas que atuam nesse ramo de mercado mobilizam-se em busca de tecnologias, estratégias e ferramentas enquanto diferencial competitivo. Desse modo, as preocupações com práticas mais sustentáveis comparecem como tendência no ramo, gerando valor adicional aos serviços prestados e produtos comercializados (Oliveira, 2018; Dickson \& Arcodia, 2010).

A ideia de sustentabilidade pode configurar-se como uma ferramenta de marketing de alto impacto competitivo. Apesar do senso comum, os princípios da sustentabilidade não se restringem somente ao fator ambiental, estando associados ao social - no sentido de construir uma sociedade justa e democrática, propondo padrões de igualdade e equidade por meio do acesso de todos aos bens e serviços de qualidade; ao cultural - chamando atenção para a necessidade de respeito e entendimento entre as diferentes nações, valorizando as características inerentes à cada cultura, e igualmente, o seu grau de desenvolvimento social e tecnológico (Sachs, 2000; Leme, Mortean, \& Brandão 2014).

Os eventos sustentáveis, por sua vez, são aqueles cujos organizadores se preocupam em reduzir os impactos negativos diretos, contribuindo para deixar um legado positivo e duradouro para a comunidade local e regional (Brasil, 2015). De acordo com Gomes (2014), além da Política Nacional de Resíduos Sólidos (PNRS) (Brasil, 2010), uma relevante mudança para despertar a atenção dos organizadores de eventos e conscientizá-los sobre o quão é importante planejar sustentavelmente os eventos é a certificação ISO 20121/2012 ${ }^{1}$, que propõe soluções para implementar um sistema de gestão e administrar os problemas do desenvolvimento sustentável em relação à realização de eventos.

A norma é uma ferramenta de gestão que pode ser aplicada de forma flexível e aperfeiçoada constantemente, estabelecendo coerência entre planejamento e realização dos eventos, com base nas necessidades dos organizadores. Nesse processo, é fundamental definir os objetivos e metas em longo prazo, determinando caminhos para torná-los reais; identificar e engajar os agentes interessados; definir os princípios que regerão o desenvolvimento sustentável; documentar os processos e monitorá-los para assegurar a efetiva comunicação entre os envolvidos (Associação Brasileira de Normas Técnicas - ABNT NBR ISO 20.121, 2012).

\footnotetext{
${ }^{1}$ Proposta pela British Standards Institute (BSI) e pela Associação Brasileira de Normas Técnicas (ABNT), tendo como referência as ações organizacionais das Olimpíadas de Londres em 2012.
} 
Além disso, é necessária a adoção de medidas que reduzam os impactos ambientais; a criação de estratégias para sensibilizar as pessoas envolvidas nos evento em relação à sustentabilidade, buscando efeitos positivos que melhorem "a imagem do evento em face de seu público participante” (Santos, 2011, p. 190). Segundo Oliveira (2018, p. 29), mesmo sendo reconhecida positivamente por todos, a sustentabilidade voltada ao setor de eventos é uma questão desafiadora aos gestores, ainda que algumas iniciativas possam ser destacadas como os "Jogos Olímpicos de Sidney na Austrália (2000), o Live Earth (2007), o SWU Starts With You (2010/2011), Rock in Rio e as Olimpíadas de Londres (2012)”.

A questão da sustentabilidade perpassa diferentes dimensões da sociedade. Os espaços livres de uso público, nesse contexto, são vistos como um ambiente viável no sentido de buscar uma forma de promover ações mais responsáveis na realização dos eventos, iniciando com a gratuidade da entrada, que permite à toda a população e aos turistas obterem momentos de lazer, de vivências, fortalecendo a cultura local em um espaço compartilhado.

A utilização desses locais pode fortalecer o Turismo de Eventos com base em princípios da sustentabilidade, uma vez que em sua essência são áreas livres de construções e que abrigam diferentes espécies da fauna e flora, podendo existir rios e córregos na paisagem e outros elementos antagônicos às áreas densamente construídas e caracterizadas pelo concreto, pela quantidade elevada de veículos automotores e seus ruídos. Ao mesmo tempo, são ambientes propícios para encontros pessoais e impessoais, sendo facilitadores das relações sociais e onde a convivência entre diferentes grupos é possível (Sobarzo, 2006; Nucci, 2008; Cunha, 2016).

A utilização dos espaços livres de uso público para a promoção de eventos pode ser um caminho estratégico para realizar ações que, de fato, valorizem o ambiente, os elementos socioculturais da cidade e a comunidade, trazendo resultados positivos para o turismo local.

\section{METODOLOGIA}

Tendo em vista o objetivo geral e a problemática do trabalho, a pesquisa foi classificada como aplicada, explicativa e de abordagem qualitativa (Gil, 2018). Os principais procedimentos metodológicos adotados foram:

I. Revisão bibliográfica e documental sobre temas como Turismo de Eventos, Sustentabilidade e Espaços Livres de Uso Público. A finalidade foi identificar e selecionar trabalhos relevantes na área (Marconi \& Lakatos, 2018). 
II. Levantamento on-line dos eventos que compõem o calendário turístico municipal e que são realizados em espaços livres de uso público na cidade. Essa consulta foi feita em sites oficiais do governo municipal, como as secretarias de esporte, de turismo e de cultura.

III. Pesquisa de campo durante os eventos possíveis de serem acompanhados empiricamente. O trabalho de campo foi auxiliado pela técnica da observação sistemática, considerada fundamental no desenvolvimento de qualquer estudo científico e indispensável para a coleta de dados (Marconi \& Lakatos, 2018; Gil, 2018).

Durante a observação sistemática, analisaram-se aspectos e práticas relevantes quando se trata dos eventos sustentáveis, por exemplo: uso do transporte público pelos participantes; parcerias com as cooperativas de reciclagem da cidade; gestão consciente de materiais, alimentos e água; articulação com associações e fornecedores locais/regionais; substituição de materiais descartados como o plástico; sensibilização da sociedade local para os possíveis benefícios dos eventos, utilizando placas, cartazes, panfletos, folders etc.; sinalizações gerais; quantidade de público, pois os impactos podem ser maiores dependendo do porte.

Esses aspectos e práticas foram selecionados, a partir das informações divulgadas pelo Serviço Brasileiro de Apoio às Micro e Pequenas Empresas (Serviço Brasileiro de Apoio às Micro e Pequenas Empresas - SEBRAE, 2017) e que podem contribuir para a redução de impactos negativos durante os eventos, tornando-os mais sustentáveis. São exemplos:

I. Conhecer o público-alvo, reconhecendo as necessidades do cliente em potencial.

II. Usar materiais recicláveis, que poderão ser reutilizados e/ou reaproveitados em um novo evento.

III. Reduzir o consumo de materiais, especialmente papeis e plásticos.

IV. Cultivar uma imagem positiva, com parcerias responsáveis e que tenham certificações oficialmente reconhecidas.

V. Planejar o descarte de resíduos sólidos com o apoio de cooperativas de reciclagem, dando uma destinação ambientalmente correta aos materiais que serão inutilizados.

VI. Diminuir a panfletagem, e a entrega desse tipo de material.

VII. Estimular a economia da região ao procurar fornecedores locais, incrementando a renda desses parceiros, e promovendo o acesso ao evento.

VIII. Informar o público sobre o uso consciente de água, o que pode ser feito por meio da capacitação e qualificação dos profissionais que trabalharão no evento.

IX. Providenciar com antecedência as autorizações exigidas por lei, conhecendo normas ambientais e outras que sejam aplicáveis aos serviços prestados.

X. Economizar a energia com luz e ventilação natural, o que pode ser maximizado em eventos realizados ao ar livre.

XI. Compensar o impacto ambiental do evento com iniciativas sustentáveis, através da compensação de carbono e plantio de árvores, por exemplo (essa questão merece uma análise mais detalhada).

XII. Diminuir as emissões de gases da logística do evento, incentivando o uso de transporte público, e carona solidária, dentre outras (SEBRAE, 2017). 
Outra técnica fundamental para a pesquisa foi a realização de entrevistas (Quadro 1).

Quadro 1 - Roteiro de perguntas utilizado nas entrevistas

1 Quais os eventos que você destacaria no calendário turístico da cidade? Por qual razão?

2 Em relação aos eventos realizados na Cidade da Criança e no Parque do Povo, você acredita que os espaços utilizados contribuem para a atratividade do evento? Por qual razão?

3 Qual a sua visão sobre o Parque do Povo para a cidade? E a Cidade da Criança?

4 Quais as potencialidades ou limitações decorrentes de utilizar um espaço livre de uso público para a realização de um evento?

5 Em relação a sustentabilidade, existem ações que subsidiam o planejamento dos eventos? E na execução?

6 Existem parcerias, por exemplo, com associações, fornecedores ou cooperativas locais para a realização de eventos?

7 Existe a preocupação com a destinação do lixo gerado durante esses eventos?

8 De que forma a população local é sensibilizada sobre a importância da sua participação nesses eventos? E em relação ao turismo local?

9 Considerando os serviços envolvidos na promoção de um evento, liste nas alternativas abaixo, as ferramentas já desenvolvidas com o objetivo de tornar os eventos mais sustentáveis?

( ) Controle no consumo de água

( ) Priorizar materiais reutilizáveis

( ) Buscar reutilizar materiais de outros eventos

( ) Monitoria quanto à quantidade de resíduos gerados no evento

( ) Visa reduzir a quantidade de resíduos gerados durante os eventos

( ) Controle no consumo de energia

( ) Controle no consumo de papeis e plásticos

( ) Tipo de matéria-prima empregada na decoração, por exemplo, que possam ser reaproveitados

( ) Destinação adequada aos resíduos gerados

( ) Monitora o desperdício de refeições servidas no evento

( ) Há processo de qualificação da sua mão de obra, por exemplo, capacitações dos funcionários

( ) Não utiliza nenhuma ferramenta de sustentabilidade

10 Você considera que ser sustentável pode agregar valor à imagem da Gestão Pública Municipal?

( ) $\operatorname{Sim}($ ) Não ( ) Não sei avaliar

Fonte: Adaptado de Oliveira, 2018, p. 21.

De acordo com Marconi e Lakatos (2018), a entrevista caracteriza-se pelo encontro entre duas pessoas, para que seja possível a troca de informações sobre determinado assunto. De maneira geral, este procedimento é bastante empregado em pesquisas sociais para: (a) averiguação de fatos, (b) determinação das opiniões sobre os fatos, (c) determinação de sentimentos etc.

Entrevistou-se os representantes da Secretaria de Turismo (SETUR) e a Secretaria de Cultura de Presidente Prudente (SECULT). Essas duas secretarias são as responsáveis pela promoção dos eventos públicos na cidade, atuando de maneira direta nos processos de planejamento, organização, realização e divulgação deles.

Também foram contactados por telefone e e-mail, os organizadores de outros eventos e representantes de secretarias, órgãos, instituições e coletivos, tais como, o/a responsável pela Cidade da Criança, pela Parada LGBTQ+, pelo Fundo Social de Solidariedade, do Consórcio Intermunicipal do Oeste Paulista (CIOP) e Secretarias de Obras e Serviços 
Públicos e de Esportes. Não houve retorno para que fosse possível o agendamento das entrevistas.

\section{ANÁLISE E DISCUSSÃO DOS RESULTADOS}

A cidade de Presidente Prudente ocupa a $8^{a}$ posição no Ranking Brasileiro do Índice de Gestão Municipal em Cultura (IGMC). É importante mencionar a representatividade do maior Centro Cultural do interior do estado, o Matarazzo, que consolidou eventos de grande porte como o Festival Nacional de Teatro de Presidente Prudente (FENTEPP) (Lamberti \& Silva, 2018).

A agenda oficial de eventos turísticos da cidade é encontrada no site da Prefeitura Municipal, sendo composta por festividades que já são conhecidas pela população local e regional (Quadro 2).

Quadro 2 - Eventos que compõem o calendário turístico em Presidente Prudente/SP

\begin{tabular}{|c|l|}
\hline MÊE & \multicolumn{1}{|c|}{ EVENTOS } \\
\hline Fevereiro & Concurso Rainha e Rei Momo do Carnaval; Carnaval Popular - Pruden Folia. \\
\hline Maio & $\begin{array}{l}\text { Caminhando com Maria; Nikkei Fest; Novittá Noivas \& Kids; Encontro Nacional das } \\
\text { Artes do Corpo - ENAC. }\end{array}$ \\
\hline Junho & Arraiá da Cidade da Criança. \\
\hline Julho & Parada do Orgulho LGBTQ+; Festival de Inverno; Concurso Comida de Boteco. \\
\hline Setembro & Expo Prudente; Desfile Cívico de 7 de Setembro; Parada Festiva. \\
\hline Outubro & Desafio de Mountain Bike; Brinca Prudente; Dia das Crianças. \\
\hline Novembro & Festival Nacional de Teatro de Presidente Prudente - FENTEPP. \\
\hline Dezembro & Inauguração da Árvore de Natal; Chegada do Papai Noel; Show de Réveillon. \\
\hline
\end{tabular}
Fonte: Adaptado de Lamberti e Silva, 2018, p. 20-23.

Os eventos realizados em espaços livres de uso público são: a Parada do Orgulho LGBTQ+, o Arraiá da Cidade da Criança, algumas ações do Festival de Inverno, o Brinca Prudente, o Dia das Crianças, a Inauguração da Árvore de Natal, a Chegada do Papai Noel e o Show de Réveillon. Esse conjunto de eventos apresenta características particulares quanto à data, porte, objetivo, local, quem os organiza, entre outros aspectos (Quadro 3).

Quadro 3 - Características dos eventos com base em informações de anos anteriores à 2020

\section{EVENTO \\ OBJETIVO}

Arraia da

Cidade das

Crianças

Mês: Junho

Porte: Grande

Parada do orgulho

LGBTQ+

Mês: Julho gratuita.
O Arraia da Cidade da Criança objetiva celebrar a data por meio de comidas típicas, brinquedos, quadrilha e música. A entrada é

O objetivo é estabelecer a empatia e estimular o exercício da cidadania dos habitantes de Presidente Prudente e região, desenvolvendo, para isso, atrações que proporcionam um contato sadio, respeitoso, festivo e didático entre a comunidade

\section{QUEM ORGANIZA}

Governo de Presidente Prudente, Cidade da Criança e a Secretaria de Turismo de Presidente Prudente (SETUR).

O Grupo Somos LGBT, o Coletivo LGBT da CUT subsede de Presidente Prudente, o 


\begin{tabular}{|c|c|c|}
\hline Porte: Grande & $\begin{array}{l}\text { LGBTQ+ e toda a sociedade, por meio de espetáculos artísticos } \\
\text { e outras intervenções culturais. }\end{array}$ & $\begin{array}{ll}\text { Levante } & \text { Popular da } \\
\text { Juventude e a Casassa } \\
\text { (Casa de Acolhimento } \\
\text { LGBT+). }\end{array}$ \\
\hline $\begin{array}{l}\text { Festival de } \\
\text { Inverno } \\
\text { Mês: Julho } \\
\text { Porte: Grande }\end{array}$ & $\begin{array}{l}\text { Tem o intuito de valorizar a gastronomia local, incentivar as } \\
\text { manifestações culturais da cidade, o lazer e estimular o turismo } \\
\text { na cidade. Apresenta shows artísticos, praça de alimentação, } \\
\text { feira de artesanato e outras atrações. }\end{array}$ & $\begin{array}{l}\text { Governo de Presidente } \\
\text { Prudente e SETUR. }\end{array}$ \\
\hline $\begin{array}{l}\text { Brinca Prudente } \\
\text { Mês: Outubro } \\
\text { Porte: Grande }\end{array}$ & $\begin{array}{l}\text { A finalidade é comemorar o Dia das Crianças proporcionado } \\
\text { diversão através de brincadeiras, brinquedos infláveis, cama } \\
\text { elástica, castelinho, entre outros. Além disso, são distribuídos } \\
\text { gratuitamente pipoca, sorvete, algodão doce e água aos } \\
\text { participantes. }\end{array}$ & $\begin{array}{l}\text { Governo de Presidente } \\
\text { Prudente, Fundo Social } \\
\text { de Solidariedade com o } \\
\text { apoio de todas as } \\
\text { secretarias municipais, } \\
\text { empresas e instituições } \\
\text { parceiras. }\end{array}$ \\
\hline $\begin{array}{l}\text { Dia das } \\
\text { Crianças } \\
\text { Mês: Outubro } \\
\text { Porte: Grande }\end{array}$ & $\begin{array}{l}\text { O foco é proporcionar uma tarde de lazer para a família e } \\
\text { comemorar de forma divertida o Dia das Crianças. A festa tem } \\
\text { distribuição gratuita de pipoca, algodão-doce e geladinho, com } \\
\text { entrada franca, brinquedos elétricos e infláveis, apresentações } \\
\text { musicais e a presença de personagens de desenhos animados. }\end{array}$ & $\begin{array}{l}\text { Cidade da Criança, } \\
\text { Secretaria de Turismo de } \\
\text { Presidente Prudente, } \\
\text { governo de Presidente } \\
\text { Prudente e Consórcio } \\
\text { Intermunicipal do Oeste } \\
\text { Paulista (CIOP). }\end{array}$ \\
\hline $\begin{array}{l}\text { Inauguração da } \\
\text { Arvore de Natal } \\
\text { Mês: Dezembro } \\
\text { Porte: Pequeno }\end{array}$ & $\begin{array}{l}\text { A árvore de Natal do bem integra a ação social, que visa } \\
\text { mobilizar pessoas e empresas para doarem cadeiras de rodas } \\
\text { para as entidades assistências e população no geral da cidade. }\end{array}$ & $\begin{array}{l}\text { Governo de Presidente } \\
\text { Prudente, SETUR e } \\
\text { Secretaria de Obras e } \\
\text { Serviço Público e Fundo } \\
\text { Social de Solidariedade. }\end{array}$ \\
\hline $\begin{array}{l}\text { Chegada do } \\
\text { Papai Noel } \\
\text { Mês: Dezembro } \\
\text { Porte: Grande }\end{array}$ & $\begin{array}{l}\text { O evento tem como objetivo criar um momento de lazer familiar } \\
\text { e proporcionar as crianças uma tarde divertida, além da chegada } \\
\text { do Papai Noel, são promovidos shows com os personagens de } \\
\text { desenhos animados e disponibilizados brinquedos infláveis, } \\
\text { como a cama elástica e pula-pula. Há distribuição gratuita de } \\
\text { pipoca, algodão doce e sorvete. }\end{array}$ & $\begin{array}{l}\text { Governo de Presidente } \\
\text { Prudente, SETUR e } \\
\text { Fundo Social de } \\
\text { Solidariedade. }\end{array}$ \\
\hline $\begin{array}{l}\text { Show de } \\
\text { Réveillon } \\
\text { Mês: Dezembro } \\
\text { Porte: Grande }\end{array}$ & $\begin{array}{l}\text { É um evento tradicional na cidade que busca proporcionar uma } \\
\text { programação de Ano Novo para as famílias da cidade e região, } \\
\text { enquanto uma opção gratuita de lazer. }\end{array}$ & $\begin{array}{l}\text { Governo de Presidente } \\
\text { Prudente e SETUR. }\end{array}$ \\
\hline
\end{tabular}

Fonte: Organizado pelo autores, 2019.

Os principais espaços livres de uso público usados na promoção dos eventos na cidade de Presidente Prudente são o Parque do Povo e o Parque Ecológico da Cidade da Criança. O Parque Ecológico da Cidade da Criança possui acesso limitado quando comparado ao Parque do Povo porque está localizado na Rodovia Raposo Tavares, S/N - Jardim Satélite. Se o turista depender de transporte público para chegar ao local, precisa se atentar aos horários dos ônibus que, aos finais de semana, por exemplo, são mais restritos.

O Parque é constituído por 172 hectares m², sendo 104 de Mata Atlântica, com diferentes espécies de árvores e animais de pequeno e grande porte, presença de lagos e bosque. A visitação é gratuita. Em relação à infraestrutura, possuí praça de alimentação, aviário, observatório, trem com passeio panorâmico, pedalinho, parque de diversões (balanço, gangorra, escorregador, gira-gira, escalada com pneus, trepa-trepa, brinquedos com corda), parque aquático (entrada paga) e outros. 
O Parque do Povo, por sua vez, abrange $460 \mathrm{mil} \mathrm{m}^{2} \mathrm{em}$ uma região privilegiada da cidade, o setor sul. Nas ruas próximas também são encontrados muitos bares tradicionais. De fácil acesso via transporte público e veículo particular, o Parque tem infraestrutura diversa com pista de skate e de caminhada, ciclovia, campo de areia, quadra poliesportiva, lanchonetes, palco fixo, centro olímpico, parque de diversões (balanço, gangorra, escorregador, gira-gira), academias para a terceira idade, iluminação urbana adequada, entre outros. Também está próximo à vários hotéis da cidade.

O Parque Ecológico da Cidade da Criança e o Parque do Povo são espaços livres de uso público considerados de boa qualidade ambiental, segundo pesquisa realizada por Cunha (2016) a respeito da qualidade dessas áreas na cidade. A autora elaborou um índice que avaliou as três funções básicas de um espaço livre de uso público: (A) Função ecológica: analisando indicadores como a disposição espacial e densidade da vegetação de porte arbóreo; os aspectos físicos e sanitários da vegetação; a cobertura predominante do solo; e a condição do relevo. (B) Função social: no qual analisaram-se o mobiliário e equipamentos existentes (infraestrutura geral); e (C) Função estética: com a análise do aspecto geral da área verde (limpeza e conservação) (Cunha, 2016).

\subsection{Eventos analisados na pesquisa de campo}

\subsubsection{Inauguração da Árvore de Natal}

A inauguração da Árvore de Natal ocorreu em 3 de dezembro às 20h. A árvore foi colocada em frente à base da Polícia Militar no Parque do Povo e ficou à mostra durante todo o mês de dezembro, sendo desmontada em 3 de janeiro de 2019. Pode-se dizer que este evento é mais direcionado à população local, já que não possuí outras atratividades além da inauguração. No dia, estiveram presentes autoridades políticas que fizeram pronunciamentos rápidos. O público presente era pequeno e logo se dispersou. A decoração da árvore contou com materiais que podem ser reaproveitados, como luzes de led (que têm maior durabilidade) e estrutura de ferro. Portanto, não foi observada nenhuma ação ou prática com fator de impacto negativo para a dimensão ambiental do espaço público, por exemplo (Figura 1). 
Figura 1 - Vista da "Árvore de Natal do Bem" em Presidente Prudente-SP

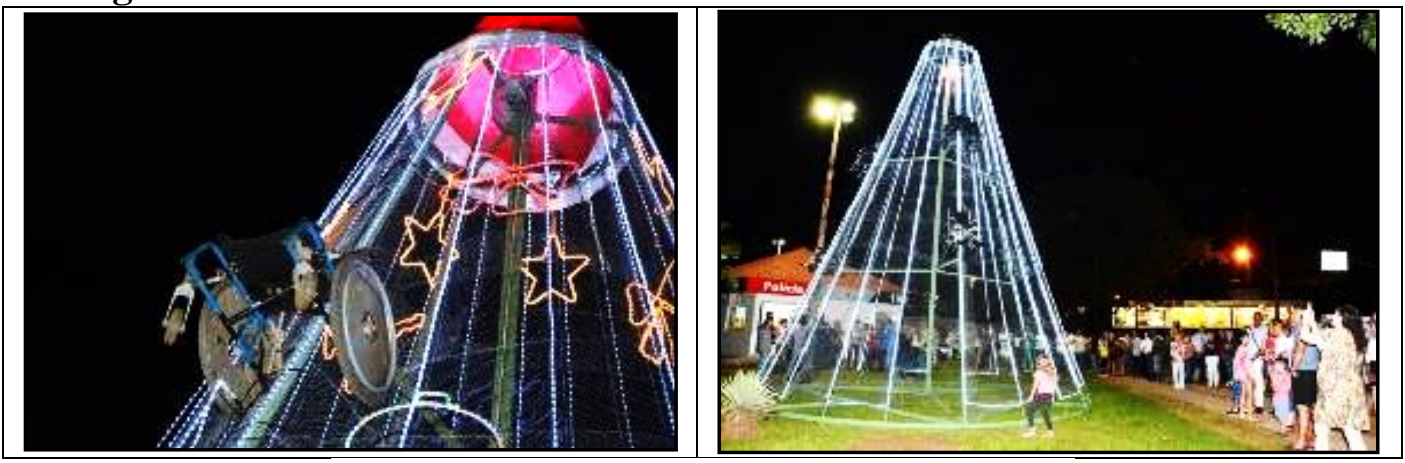

Fonte: Secretaria Municipal de Comunicação, 2018².

Por outro lado, a Árvore do Bem, como ficou conhecida, tem uma representatividade social relevante. A árvore que foi decorada com cadeiras de rodas em desuso, faz parte de uma campanha do Governo Municipal para arrecadar cadeiras de rodas para as entidades assistenciais da cidade e para a população de modo geral. Outros instrumentos também são coletados, como muletas, andadores e outros que podem facilitar a mobilidade de quem necessita. Para a cidade e para o turismo local, infere-se que esta iniciativa pode incentivar a visitação de pessoas no Parque do Povo, além de fortalecer positivamente a imagem da gestão pública e organizadores porque a ação tem como finalidade melhorar a qualidade de vida da população. Além de despertar para as possibilidades beneficentes da promoção dos eventos.

\subsubsection{A Chegada do Papai Noel}

A Chegada do Papai Noel aconteceu no dia 16 de dezembro de 2018 em frente ao Chalé do Fundo Social, no Parque do Povo. O evento teve início às $18 \mathrm{~h}$ e contou com a presença de autoridades políticas, que tiveram um momento para a fala. Além da chegada do Papai Noel, outras ações foram promovidas como as apresentações de personagens de desenhos animados e da Fanfarra da Escola Estadual de Ensino Integral Joel Antônio de Lima Genésio, do Jardim São Gabriel, regida pelo maestro Reginaldo Branco. No evento, o Papai Noel tirou fotos e conversou com as crianças, conforme a ordem da fila formada (Figura 2).

Durante a festividade, houve a distribuição gratuita de pipoca, algodão doce, sorvete, água e balões. Também disponibilizaram brinquedos para que as crianças pudessem se divertir. Em conversa com o locador dos brinquedos foi verificado que se tratava de um residente do município.

${ }^{2}$ Recuperado de: http://www.presidenteprudente.sp.gov.br/site/noticias.xhtml?cod=40852 
Figura 2 - Vista parcial da Chegada do Papai Noel no Parque do Povo

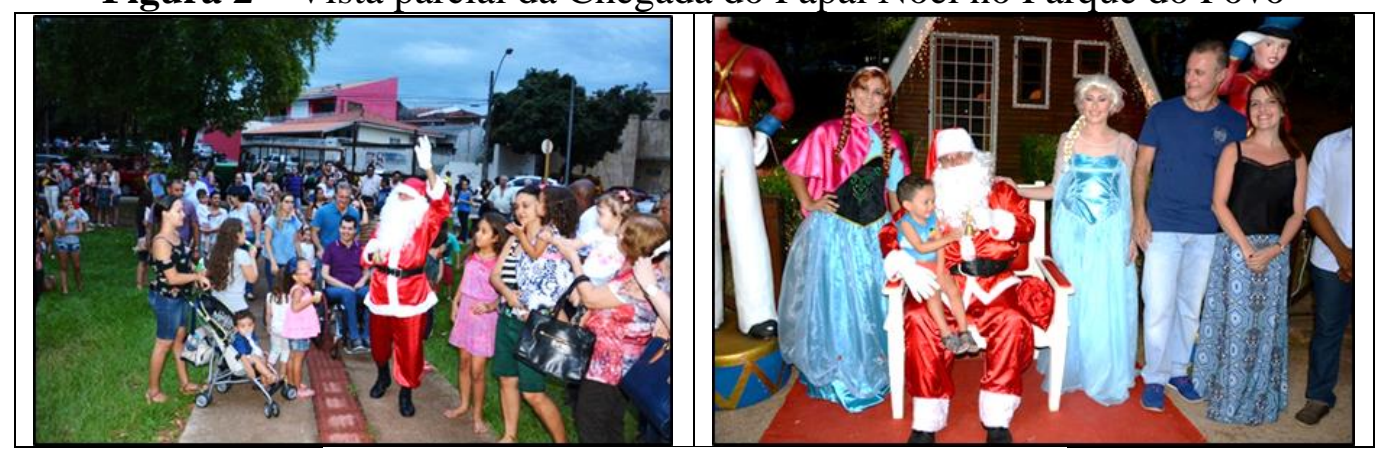

Fonte: Secretaria Municipal de Comunicação, $2018^{3}$.

Diferentemente do evento "Inauguração da Árvore de Natal, com o dispersar do público por volta das $22 \mathrm{~h}$, o descarte do lixo produzido ficou evidente no Parque. A distribuição gratuita de materiais pode ter contribuído para um consumo maior deles, refletindo na geração de mais lixo. Além das lixeiras fixas existentes no local, havia lixeiras móveis que ficaram totalmente cheias.

No gramado, nos bancos e na área de entorno do Parque foi possível notar a presença de lixo (Figura 3). Este evento reuniu um número expressivo de pessoas, por isso, pode-se dizer que a infraestrutura disponível para a deposição de lixo não foi suficiente para atender a demanda do público. Não foi observada sinalização indicando a presença das lixeiras em outros lugares do parque ou próximas de onde o evento estava sendo realizado. O ideal seria pensar em uma melhor forma de disposição delas, considerando a alocação de mais lixeiras em áreas com alta concentração de pessoas.

Figura 3 - Vista parcial das lixeiras removíveis disponibilizadas no local

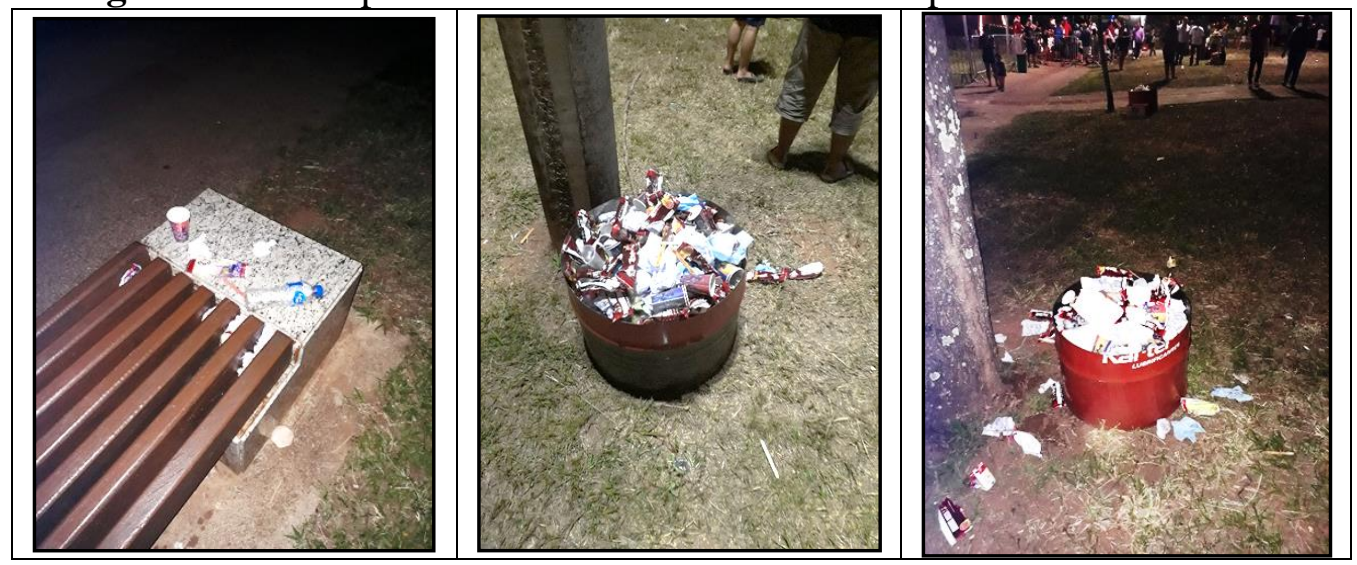

Fonte: Fotos dos autores, 2018.

${ }^{3}$ Recuperado de: http://www.presidenteprudente.sp.gov.br/site/noticias.xhtml?cod=40852 
Uma ressalva interessante é que algumas iniciativas no Brasil mostram a efetiva incorporação das lixeiras ao evento. Além de servirem como local para o descarte do lixo, também são utilizadas estrategicamente como elementos decorativos e onde podem ser promovidas as marcas dos apoiadores e patrocinadores do evento.

Como era um evento de grande porte, esperou-se que os organizadores informassem o público sobre a necessidade da correta destinação do lixo e da importância em manter o espaço em bom estado de conservação. Como não foi levantada esta questão, gerou-se um impacto negativo e uma poluição paisagística temporária. Todavia, no dia seguinte a realização do evento, os funcionários da prefeitura estiveram no local para fazer a limpeza e retirada dos resíduos produzidos no dia anterior.

A respeito do acesso, observou-se grande quantidade de veículos estacionados ao redor do Parque e grande rotatividade de ônibus, já que vários pontos de ônibus estão distribuídos ao longo da área. A acessibilidade ao Parque do Povo é um elemento positivo no que se refere à sua utilização para a realização de eventos. Em síntese, nota-se que esta festividade gera impactos sociais positivos para a comunidade, já que ela é beneficiada diretamente com a realização do evento. Da mesma forma, analisando as placas dos carros estacionados nas vagas de estacionamento, percebeu-se a atratividade que o evento gera nas cidades do entorno mais próximo. Com isso, é possível que a movimentação turística tenha sido maior neste dia e, consequentemente, o uso da infraestrutura e dos serviços locais, gerando renda para o município.

\subsubsection{Arraiá da Cidade das Crianças}

O Arraiá ou Festa Junina da Cidade da Criança, foi realizado dia 30 de junho de 2019, com início às $13 \mathrm{~h}$ e encerramento às $16 \mathrm{~h} 30$. O evento aconteceu no Parque Ecológico Cidade da Criança. Com atrativos para o público presente, distribuíram gratuitamente pipoca, algodão-doce e amendoim. Havia brinquedos infláveis distribuídos no local, para que as crianças pudessem se divertir de forma gratuita. Além disso, o público podia adquirir outros alimentos e bebidas nas lanchonetes existentes. No local, também havia bebedouros de água para consumo gratuito, que é uma infraestrutura do próprio Parque. As atrações principais foram a Peça "Os Três Porquinhos" e a "Quadrilha da Paróquia São Pedro", ação já tradicional nesse evento (Figura 4). 
Figura 4 - Movimentação de pessoas durante o evento

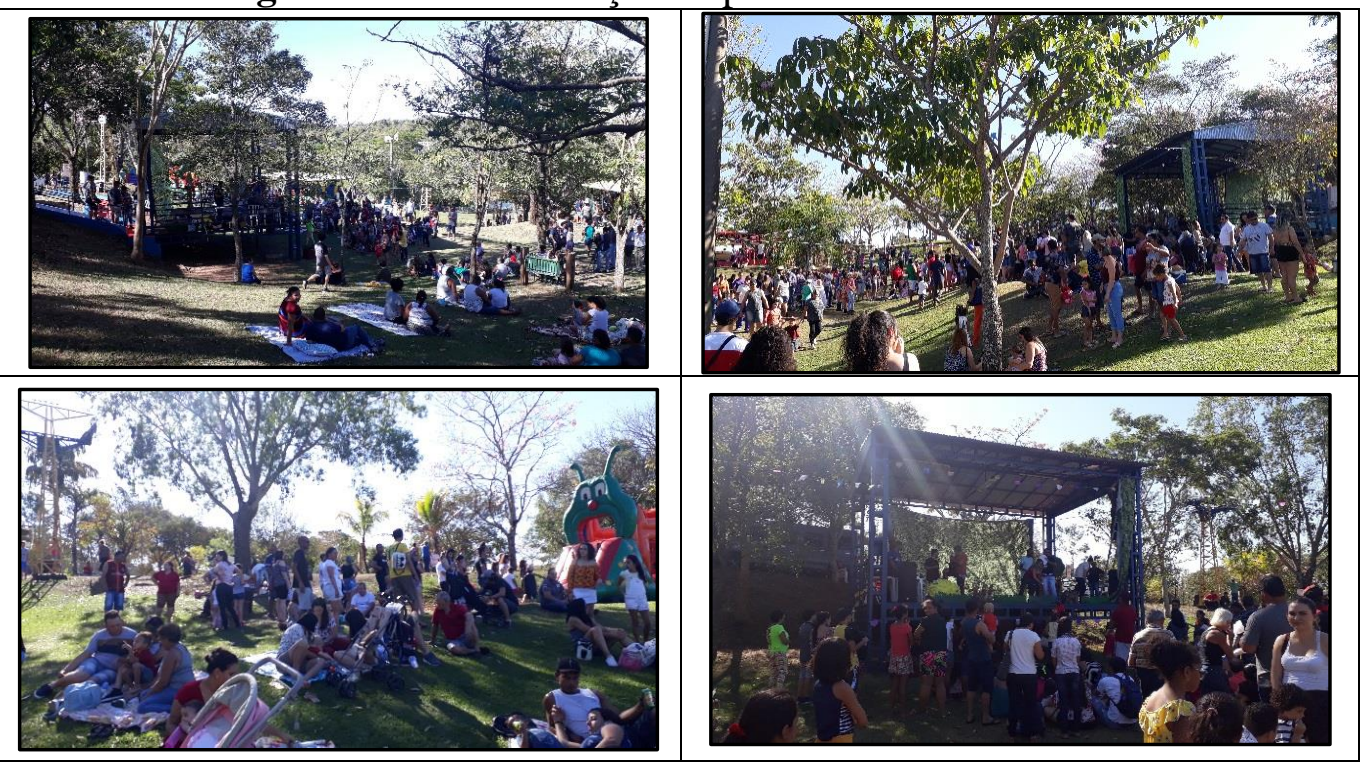

Fonte: Fotos dos autores, 2019.

Outra atratividade presente, mas que não estava na programação, foi o "Trenzinho Furacão", que realizou passeios dentro do Parque Ecológico, mediante compra de convite à $\mathrm{R} \$ 5,00$ por pessoa. O percurso foi animado pelos personagens Homem-Aranha, Fofão, Chiquinha e Nhonho, que divertiram os passageiros com coreografias e brincadeiras (Figura $5)$.

Figura 5 - Movimentação em torno do "Trenzinho Furacão"

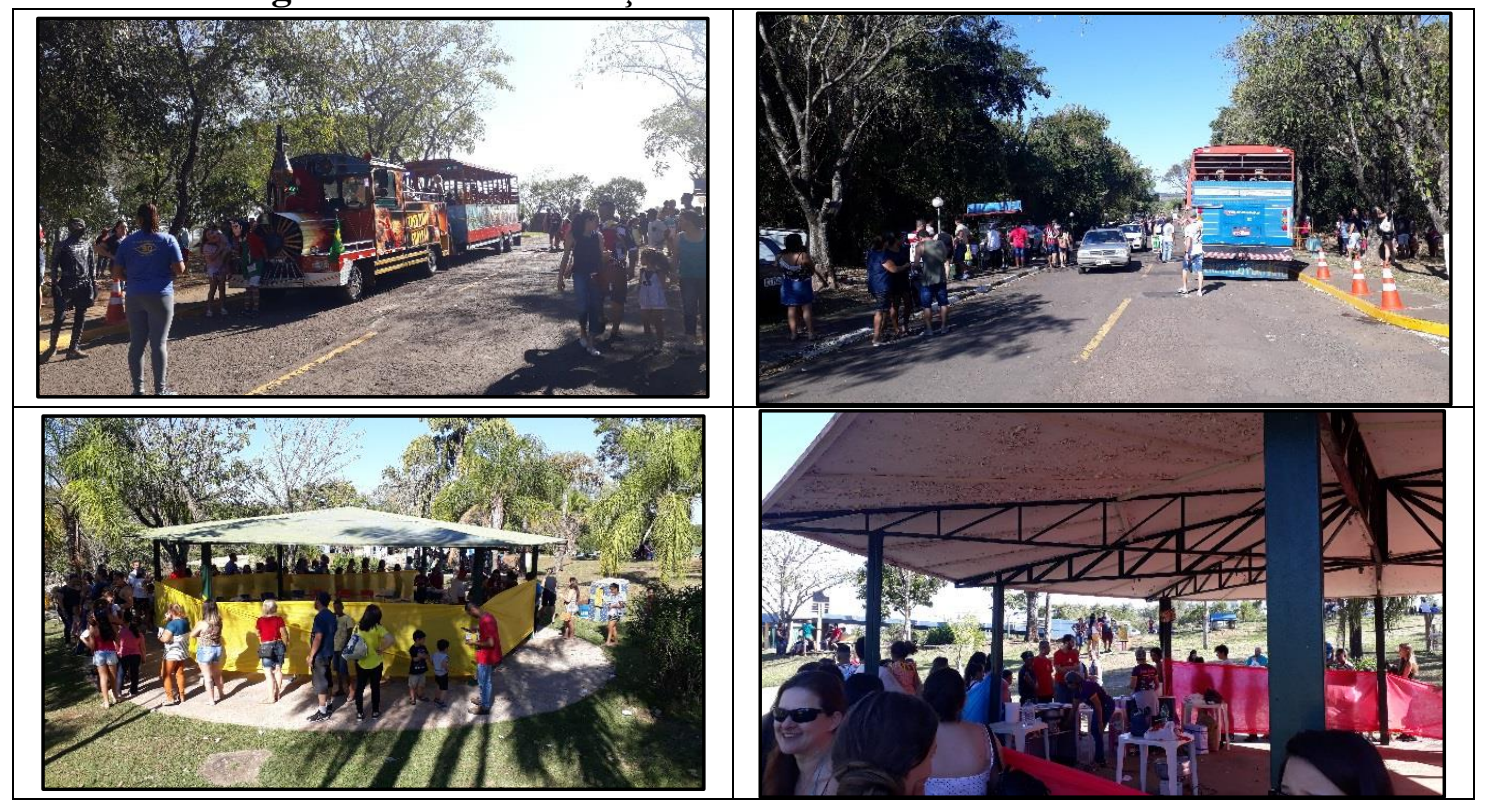

Fonte: Fotos dos autores, 2019.

Em conversa informal com os trabalhadores no evento, verificou-se que tanto os brinquedos infláveis quanto os alimentos distribuídos, eram de uma empresa de recreação 
local. Acredita-se que essa atitude incentiva os moradores da cidade a valorizarem e a utilizarem os serviços prestados. Além de motivar a participação desses parceiros nos eventos promovidos e que constituem o calendário turístico.

Como mencionado anteriormente, o Parque está localizado distante da malha urbana da cidade. Como o acesso por meio de transporte público fica limitado aos finais de semana, observou-se a grande presença de automóveis particulares (Figura 6). Foi possível notar que muitas pessoas chegavam ao local por meio de serviços de aplicativo, como de Táxi, Uber, 99 etc. Devido à movimentação, gerou-se trânsito e um pequeno transtorno para se achar uma vaga livre no estacionamento, mas havia uma equipe auxiliando para que o congestionamento fosse amenizado.

Por meio da análise das placas dos automóveis, verificou-se que a origem do público era diversa, demostrando que o evento não atrai somente a população local, mas que exerce influência em toda a região do entorno, como Indiana-SP, Dracena -SP, Alvares MachadoSP, Presidente Epitácio -SP, Bataguassu -MS. Outras mais distantes foram identificadas, como Campo Grande-MS, Sorocaba-SP, São Paulo-SP e Paraguaçu Paulista -SP.

Figura 6 - Visão parcial do estacionamento

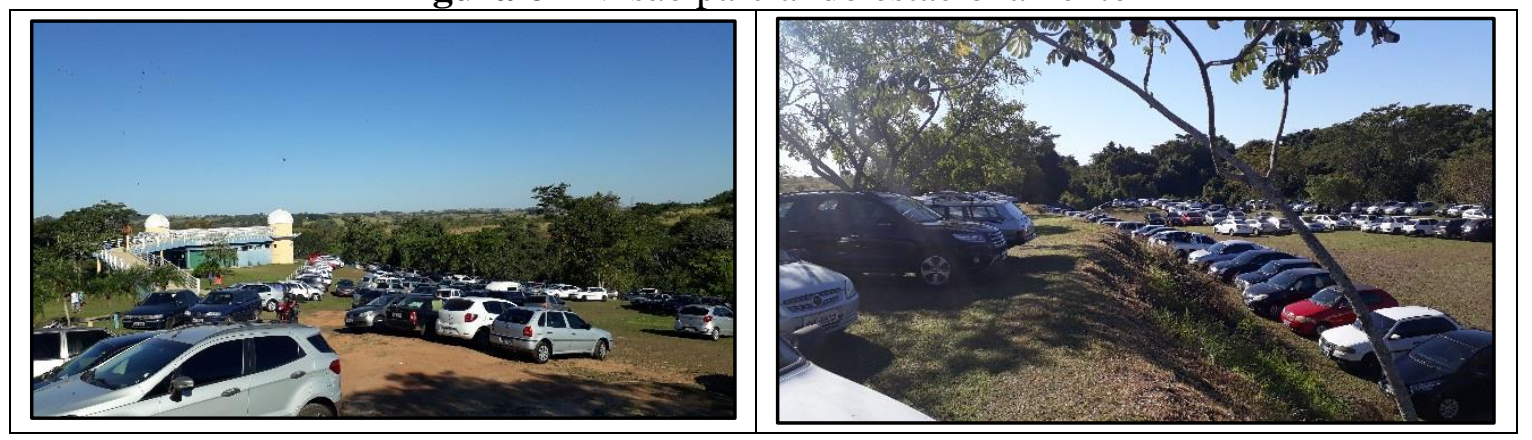

Fonte: Fotos dos autores, 2019.

A possível presença de visitantes de outras cidades, reforça a importância do evento para a cidade e para a utilização daquele ambiente de lazer, mostrando que o uso de áreas verdes públicas para a promoção de eventos, de fato incentiva o turismo e movimenta a economia local. Nesse evento, uma ação dos organizadores teve destaque merecido: durante as apresentações que ocorreriam no palco com o sorteio de brindes, direcionaram recados para o público sobre importância do descarte do lixo de maneira correta e consciente, como "Lugar de lixo é no lixo", "Não jogar lixo no chão". Essa atitude, apesar de simples, é uma maneira viável de sensibilizar a população em relação ao descarte dos materiais, maximizando os impactos positivos do evento. Além dos recados, no Parque havia um número expressivo de lixeiras, estrategicamente distribuídas próximas ao grande fluxo de visitantes (Figura 7). 
Figura 7 - Vista parcial das lixeiras existentes do Parque Ecológico Cidade da Criança
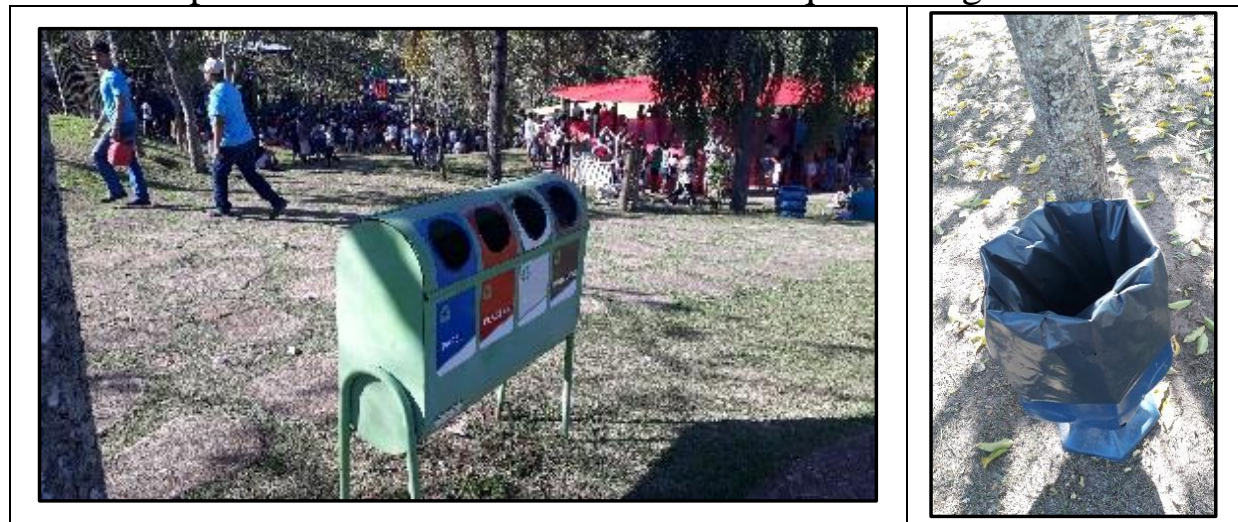

Fonte: Fotos dos autores, 2019.

O modo como o evento foi desenvolvido, demonstrou que o planejamento ocorreu de maneira organizada e dinâmica, o que fez toda a diferença para chamar a atenção do público e criar um ambiente de descontração e lazer entre as famílias presentes, que utilizaram o gramado para estender as suas toalhas e usufruir daquele momento e espaço.

\subsubsection{Parada LGBTQ+}

A $13^{\text {a }}$ Parada do Orgulho LGBTQ+ de Presidente Prudente aconteceu no dia 14 de julho no Parque do Povo. A concentração para a caminhada pelo parque teve início às 14h, próximo à Avenida Brasil, com destino ao palco principal, no qual ocorreram as atrações. Para que o evento ocorresse de maneira positiva, a Secretaria Municipal de Mobilidade Urbana e Cooperação em Segurança Pública (SEMAV) prestou o auxílio necessário, tanto na escolta como no bloqueio das vias de acesso que seriam utilizadas pelo Trio Elétrico (Figura 8).

Como proposto na programação do evento, às $16 \mathrm{~h}$ teve início os shows dos artistas locais no palco montado sobre o gramado do Parque do Povo. Esse foi o local onde as pessoas se aglomeraram. A disposição das barracas, nas quais havia comércio de alimentos e bebidas, interferiu na visualização do palco pelo público. Assim, foi criada uma divisão pouco favorável para o uso do espaço, situação que dificultou a comodidade das 7 mil pessoas presentes no evento. 


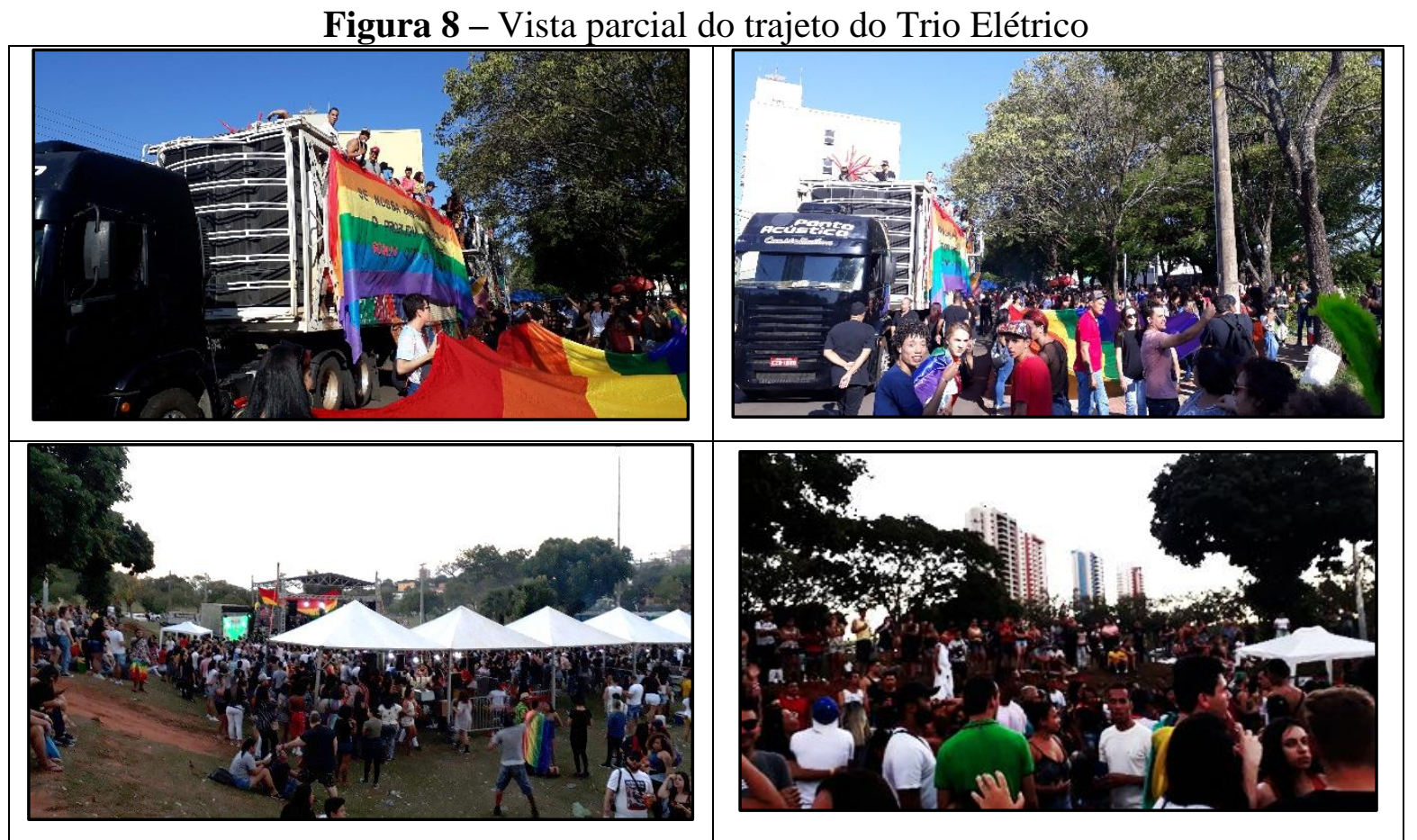

Fonte: Fotos dos autores, 2019.

Nesse evento, o cronograma de atrações apresentou algumas falhas, como a interrupção de algumas atratividades, o que gerou desconforto em quem estava prestigiando o evento, possivelmente causando um impacto negativo na experiência dos visitantes. Analisando os automóveis estacionados ao redor do Parque e observando a chegada das pessoas, notou-se que muitos vierem por meio de excursões de cidades da região, como de Dracena/SP, Bataguassu/MS, Presidente Epitácio/SP, Adamantina/SP, Assis/SP e Londrina/PR. Do mesmo modo, a grande presença de veículos particulares evidenciou a atratividade do evento, tanto para os moradores da cidade quanto os de outras localidades. $\mathrm{O}$ transporte público também foi fortemente utilizado para chegar até o local, apesar de ter suas rotas alteradas quando o trio se locomovia e as vias estavam interditadas.

Do ponto de vista ambiental, algo preocupante e que não teve nenhuma sensibilização durante todo o evento, foi a questão dos resíduos sólidos gerados. A presença de lixeiras era mínima. Utilizaram somente a infraestrutura fixa do Parque, que não atendeu o porte do evento e a necessidade dos participantes. Foi notado alguns "sacos de lixo" aleatoriamente colocados em alguns locais, mas sem sinalização indicando a sua presença ali.

Essa situação levou o público a descartar os resíduos no chão, sem preocupações com os impactos para o ambiente. O encerramento oficial do evento foi às $23 \mathrm{~h}$, mas o aglomerado de pessoas se dispersou apenas uma hora depois. No dia posterior, pela manhã, era possível observar a quantidade de materiais descartados no Parque do Povo. Essa condição levou à uma revolta por parte da população local, que se sentiu prejudicada pelo evento, já que se 
trata de uma área verde utilizada para várias finalidades. $\mathrm{O}$ desconforto por causa do evento foi expresso nas redes sociais, em uma página oficial da cidade, na qual as pessoas fizeram inúmeras críticas à organização do evento (Figura 9).

Figura 9 - Vista parcial do Parque do Povo, com destaque para o descarte de materiais

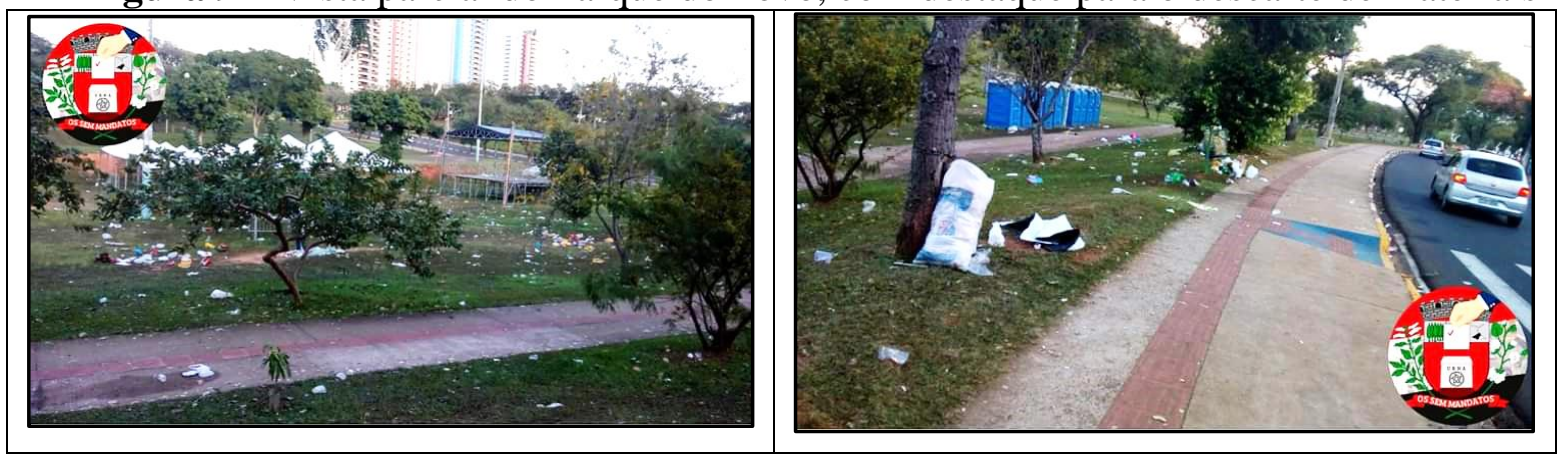

Fonte: Prudente Imprudente, 2019.

A organização do evento foi criticada porque não considerou a necessidade de reforços na infraestrutura, especialmente, por se trata de um evento de grande porte. $\mathrm{O}$ trabalho da Companhia Prudentina de Desenvolvimento (PRUDENCO), empresa responsável pela limpeza, não foi suficiente para as necessidades do evento.

Apesar dos impactos positivos para a cidade em outras dimensões, como a movimentação no comércio ao redor do Parque e a possibilidade de vendas no próprio evento, bem como a questão social que esse evento defende e valoriza, a questão do lixo foi o grande legado para a população da cidade. Diante disso, é indispensável repensar esse assunto para as próximas edições, especialmente, propondo alternativas para a sensibilização do público no local, já que se trata de uma área verde, muito utilizada pelos munícipes.

\subsection{Entrevistas}

Os resultados das entrevistas indicam que o órgão mais ativo na organização e realização de eventos em áreas verdes públicas da cidade, é a SETUR. Todavia, ambas as secretarias demonstram a sua importância na dinamização dos eventos na cidade, com o objetivo de proporcionar lazer a entretenimento para a população e turistas, porém trabalhando com ferramentas diferentes.

Os entrevistados pontuaram a relevância e o potencial das áreas verdes em Presidente Prudente, principalmente o Parque do Povo - "A praia de Prudente" e da Cidade da Criança, por sempre estarem em destaque e serem utilizados como os espaços de lazer, de grande parte da população. No caso do Parque do Povo, as potencialidades, segundo os representantes das secretarias, estariam ligadas à sua localização privilegiada, a estrutura presente como o centro 
olímpico, que será reinaugurado brevemente. Já a Cidade da Criança, exerce atratividade por causa de seus projetos ecológicos e infraestrutura diversificada.

É importante destacar que realizar eventos em áreas verdes públicas tem limitações, como a questão da segurança, apesar de não ter sido pontuado pelos entrevistados, é um aspecto relevante já que se trata de um espaço amplo e aberto, onde não se pode ter o controle de tudo o que está acontecendo. Outra limitação diz respeito à burocracia dos alvarás e autorizações, assim como legislações municipais que devem ser cumpridas, como Termo de Ajustamento de Conduta (TAC), e em conformidade com a fiscalização da Prefeitura e do Corpo de Bombeiros. Questionados sobre essas questões, os entrevistados pontuaram que existem critérios ambientais da própria Prefeitura, mas não souberam especificar quais eram.

Já buscando relacionar com a temática da sustentabilidade, os entrevistados mencionaram que acreditam na valorização dos eventos e das ações de planejamento e organização quando baseadas em práticas que reduzem impactos negativos em todas as dimensões da sociedade. Para ambos, a existência de parcerias entre órgãos municipais e as instituições privadas é importante para que haja incentivos fiscais, no pré-evento, durante o evento e no pós-evento. Foi citado nas duas entrevistas, a condição da Prudenco, como empresa responsável por recolher e descartar de forma correta os resíduos sólidos gerados no evento. Essa é parceria válida, mas que pode não atender as reais necessidades dos eventos, especialmente se for de grande porte, como é o caso da Parada.

Quando perguntados sobre a sensibilização da população para a sua efetiva participação nos eventos e em relação ao turismo local, foi dito que as estratégias de divulgação são, prioritariamente, realizadas via redes sociais, porque atinge grande número de pessoas e gera um custo de publicidade baixo para as secretarias. Para os entrevistados, o marketing digital é uma ferramenta assertiva e eficaz.

É importante mencionar que como sustentável foi discutido somente a questão do descarte dos resíduos sólidos. Não mencionaram, espontaneamente, outras práticas possíveis e realizadas nos eventos. Todavia, quando questionados sobre ações mais específicas, ambos os entrevistados afirmaram promover em suas secretarias, atitudes positivas e responsáveis. No caso da Secretaria de Turismo, existe um "Plano de Sustentabilidade" com foco na redução de despesas desnecessárias e respeito ao meio ambiente. Por outro lado, nos eventos, é difícil incorporar, de fato, ações sustentáveis.

Normalmente, os materiais utilizados na decoração são reutilizados. Para os entrevistados, a realização de eventos nas áreas verdes públicas, não gera consumo de energia além do padrão, já que ambos os locais ficam, por exemplo, com a iluminação ligada durante 
o período noturno. Para os entrevistados, algumas ações são mais difíceis de serem colocadas em prática, como a monitoria quanto à quantidade de resíduos gerados no evento; o controle no consumo de papeis e plásticos; o desperdício de alimentos etc.

Não existe plano de ação previamente elaborado, com foco no monitoramento dos impactos e na aplicação de práticas de sustentabilidade nos eventos. O que há, quando há, é o lembrete sobre a necessidade de descartar os materiais gerados nas lixeiras. Apesar de válida, essa ação é muito simples, quando comparada às dimensões da sustentabilidade e os reais impactos gerados pelos eventos realizados em áreas verdes públicas.

\section{CONSIDERAÇÕES FINAIS}

De modo geral, a ação mais praticada nos eventos e reconhecida como sustentável é o incentivo à utilização de materiais que possam ser reciclados e/ou reutilizados. Todavia, existem outros aspectos que precisam ser valorizados como o aproveitamento dos elementos culturais, ambientais e econômicos locais, a inclusão social, a acessibilidade, a utilização dos sistemas de transportes de uso coletivo e a própria sensibilização ambiental de todos os envolvidos na promoção do evento (SEBRAE, 2017; Ahmad, Abdul, Rashid, \& Yusof, 2013).

Dessa maneira, a utilização dos espaços livres de uso público para a realização de eventos também é considerada uma alternativa que possibilita a incorporação dos princípios da sustentabilidade, de forma responsável. Isso é possível por meio da atuação dos organizadores, que precisam enxergar todo o potencial disponível nesses espaços, como a paisagem natural, o contato entre pessoas de diferentes grupos, a valorização do ambiente público, a gratuidade na participação das práticas culturais, entre outros fatores. É preciso propor ações de valorização e ocupação dos espaços públicos na cidade.

Em Presidente Prudente, os eventos realizados em espaços livros de uso público, como no Parque do Povo e Parque Ecológico Cidade da Criança, mostram que é possível atingir dimensões da sustentabilidade, sobretudo, no que se refere às demandas sociais e econômicas. A utilização desses locais motiva a sua ocupação pela sociedade, como foi visualizado no trabalho de campo. A presença da população local e dos turistas podem ser aproveitadas pelos organizadores para a valorização dessas áreas, gerando vínculos, lembranças e memórias. Além disso, por se tratar de espaços de lazer gratuitos, acredita-se que esses eventos propiciem qualidade de vida, além de reforçar os elementos culturais e ambientais locais, melhorando a imagem da cidade e da gestão pública municipal. 
Em relação aos aspectos econômicos, enquanto impactos positivos destacam-se: I) A valorização e possivelmente maiores investimentos financeiros nessas áreas, que muitas vezes são utilizadas como "terrenos baldios" pela população que joga seu lixo; II) Utilização de elementos naturais da paisagem, evitando gastos com itens decorativos que serão descartados posteriormente; III) Utilização da luz solar, no caso de eventos no período da manhã ou tarde, diminuindo gastos com a energia elétrica; IV) Movimentação da economia local, já que os participantes fazem uso de toda a infraestrutura existente na cidade, especialmente, nos locais próximos aos espaços de realização do evento.

Todavia, é importante mencionar que os eventos continuam impactando negativamente a dimensão ambiental dos espaços livres de uso público, pois há o descarte inadequado dos resíduos sólidos no chão em todos os eventos. Essa situação gera poluição visual, degradando a paisagem e o ambiente. Também podem ser citados impactos sobre a vegetação de gramado existente na área, dependendo do número de pessoas que participam do evento.

A partir dos resultados obtidos com a pesquisa, sugere-se aos organizadores que no seu processo de planejamento sejam pensadas práticas de sensibilização dos envolvidos, desde os responsáveis até o público participante. Podem ser inseridas nos locais, placas com mensagens de conscientização, ações de marketing digital, comerciais em emissoras de televisão local, assim como recados durante a programação, algo que já é praticado em algumas festividades. Da mesma forma, é interessante repensar os processos de descarte e coleta dos resíduos sólidos para que não sejam acumulados no local do evento. Acredita-se que o maior engajamento dos organizadores na divulgação dos ganhos e dos benefícios gerados com a realização desses eventos nessas áreas, pode promover ainda mais a sua valorização por parte dos munícipes.

A utilização dos espaços livres de uso público é considerada neste trabalho, uma ferramenta significativa de promoção dos eventos com base na sustentabilidade. Essas áreas constituem-se em recursos ambientais disponíveis no espaço da cidade e pela própria característica natural, pode incorporar de maneira positiva as diferentes dimensões da sustentabilidade no setor de eventos, congregando elementos como a fauna e flora, por exemplo, além de serem propícias para encontros pessoais e impessoais, facilitando as relações socioculturais entre os diferentes grupos da sociedade (Nucci, 2008).

Para pesquisas futuras, a fim de detalhar e superar algumas limitações encontradas durante a realização deste trabalho, como o conhecimento da percepção do público participante nos eventos, sugere-se analisar como as pessoas enxergam a realização de 
eventos nesses locais da cidade. Essa informação é interessante, sobretudo, para compreender como os participantes reconhecem os impactos, tanto positivos quanto negativos, quando ocupam aquele local para participarem de um evento.

Diante dos resultados e discussões apresentadas, considera-se que a principal contribuição desta pesquisa é a demonstração de como os espaços livres de uso público apresentam potencial para a promoção de eventos mais sustentáveis, gerando benefícios para a cidade, comunidade e organizadores. Para tanto, é indispensável que sejam incorporadas no processo de planejamento, ações que reduzem os impactos negativos advindos com a realização dos eventos nesses locais.

\section{AGRADECIMENTOS}

Agradecimentos ao Conselho Nacional de Desenvolvimento Científico e Tecnológico (CNPq) pela concessão da bolsa de iniciação científica e ao Centro Paula Souza - Fatec, por todo apoio estrutural e docente.

\section{REFERÊNCIAS}

Ahmad, N. L., Abdul, N., Rashid, W. E., \& Yusof, A. N. (2013). Green Event Management and Initiatives for Sustainable Business Growth. International Journal of Trade Economics and Finance.

Albuquerque, S. S. (2004). A importância dos eventos para o desenvolvimento turístico. Monografia (Especialista em Gestão de Marketing no Turismo). Universidade de Brasília, Brasília, DF, Brasil.

Associação Brasileira de Normas Técnicas - ABNT. (2012). NBRISO20121 de 07/2012. Sistemas de gestão para sustentabilidade de eventos - Requisitos com orientações de uso.

Brasil. Lei $n^{o}$ 12.305, de 2 de agosto de 2010. (2010). Institui a Política Nacional de Resíduos Sólidos; altera a Lei no 9.605, de 12 de fevereiro de 1998; e dá outras providências. Brasília, DF. Recuperado de http://www.planalto.gov.br/ccivil_03/_ato2007-2010/2010/lei/112305.htm

Brasil. Ministério do Meio Ambiente - MMA. (2015). Dicas para tornar seu evento sustentável. Recuperado de http://a3p.ana.gov.br/Documents/docs/outros/DicasParaTornarSeuEventoSustentavel.pdf

Brasil. Ministério do Turismo. (2006). Segmentação do Turismo: Marcos Conceituais. Brasília, DF: Ministério do Turismo.

Cunha, M. C. S. (2016). Diagnóstico da qualidade ambiental nas áreas verdes públicas em Presidente Prudente (SP). Dissertação (Mestrado em Geografia). Programa de Pós-Graduação 
em Geografia da Faculdade de Ciências e Tecnologia. Universidade Estadual Paulista, Presidente Prudente, SP, Brasil.

Dickson, C., \& Arcodia, C. (2010). Environmentally sustainable events: a critical review of the literature. Rettrieved from

https://www.academia.edu/27168542/Environmentally_sustainable_events_a_critical_review _of_the_literature

Gastal, S. (2007). Turismo, políticas públicas e cidadania. São Paulo: Aleph.

Gil, A. C. (2018). Como elaborar projetos de pesquisa. (6a. ed.). São Paulo: Atlas.

Gomes, A. A. (2014). Gestão de resíduos sólidos como estratégia de sustentabilidade ambiental nos grandes eventos. Dissertação (Mestrado em Turismo). Universidade de Brasília, Brasília, DF.

Lamberti, D. C., \& Silva, R. L. (2018). Segmentação de Mercado: As repercussões do turismo de eventos em Presidente Prudente - SP. Monografia (Curso Superior de Tecnologia em Eventos). Faculdade de Tecnologia - FATEC, Presidente Prudente, SP, Brasil.

Leme, P. C. S., Mortean, A. F., \& Brandão, M. S. (2014). Sustentabilidade em eventos acadêmicos: guia prático para Instituições de Educação Superior. São Carlos, SP. EESC-USP.

Marconi, M. A., \& Lakatos, E. M. (2018). Metodologia científica. (7a. ed.). São Paulo: Atlas.

Meirelles, G. F. (1999). Tudo sobre eventos: o que você precisa saber para criar, organizar e gerenciar eventos que promovem sua empresa e seus produtos. São Paulo: STS.

Nucci, J. C. (2008). Qualidade Ambiental e adensamento urbano: Um estudo de ecologia e planejamento da paisagem aplicado ao distrito de Santa Cecília (MSP). (2a. ed.). Curitiba: O Autor.

Oliveira, A. M. (2018). Ações sustentáveis para a promoção de eventos: estudo a partir da visão de gestores. Monografia (Curso Superior de Tecnologia em Eventos). Faculdade de Tecnologia - FATEC, Presidente Prudente, SP, Brasil.

Sachs, I. (2000). Caminhos para o desenvolvimento sustentável. Rio de Janeiro: Garamond.

Santos, M. D. (2011). Eventos verdes. In: Matias, M. (Org.). Planejamento, organização e sustentabilidade em eventos: culturais, sociais e esportivos. Barueri: Manole.

Serviço Brasileiro de Apoio às Micro e Pequenas Empresas - SEBRAE. (2017). Eventos Sustentáveis.

Silberberg, C. P., \& Macdowell, D. (2010). Gestão ambiental e responsabilidade social em eventos. In: Philippi Jr., A., \& Ruschmann, D. V. M. Gestão ambiental e sustentabilidade no turismo. Barueri, SP: Manole.

Smith-Christensen, C. (2009). Sustainability as a concept within events. Event management and sustainability, 22-30. 
Sobarzo, O. (2006). A Produção do Espaço Público: da Dominação à Apropriação. GEOUSP Espaço e Tempo, 10(2), 93-111.

Tomazzoni, E. L. (2003). Dimensão cultural do turismo. Anais... VIII Congresso Brasileiro de Ciências da Comunicação da Região Sul. Passo Fundo - RS.

FORMATO PARA CITAÇÃO DESTE ARTIGO

SOUZA, M. C. C., \& PÁDUA, D. (2021). Estudo sobre ações sustentáveis para a organização de eventos em espaços livres de uso público. Revista de Turismo Contemporâneo, 9(3), 405429. https://doi.org/10.21680/2357-8211.2021v9n3ID21496 